\title{
RESEARCH
}

Open Access

\section{The effects of persistent drought and waterlogging on the dynamics of nonstructural carbohydrates of Robinia pseudoacacia L. seedlings in Northwest China}

Bin Yang ${ }^{1}$, Changhui Peng ${ }^{1,2^{*}}$, Qiuan Zhu', Xiaolu Zhou' ${ }^{1}$, Weiguo Liu', Min Duan ${ }^{1}$, Hui Wang ${ }^{1}$, Zhihao Liu', Xinyi Guo ${ }^{1}$ and Meng Wang ${ }^{3}$

\begin{abstract}
Background: The nonstructural carbohydrates (NSCS) of plants are posited to be crucial traits for the resistance and resilience of plants to climate change-induced drought and flooding. However, the potential effects of persistent drought and waterlogging on the dynamics of the NSCs and the underlying mechanisms are still poorly understood.

Methods: We measured the NSCs concentrations and pool size, photosynthetic rate and biomass of Robinia pseudoacacia L. seedlings for both 2015 and 2016 under five soil water treatments: 3\%, 8\%, 17\%, 24\% and 34\% soil water content, representing extreme drought (ED), moderate drought (MD), the control group (CG), field capacity (FC) and waterlogging (WL) stresses, respectively. We observed the relationship between the pool size of NSCs and the survival of seedlings under water stress (drought and waterlogging) for 30 days in greenhouse.

Results: Compared with CG, the net photosynthetic rate decreased $91 \%, 67 \%, 34 \%$ and $71 \%$, and the biomass decreased by 37\%, 15\%, 16\% and 33\% under ED, MD, FC and WL, respectively. The total NSC (TNSC) concentration was significantly increased by $154 \%$ under ED after 10 days and sharply decreased by $50 \%$ under ED after 30 days. The concentrations of soluble sugars (SS) were significantly increased by 100\% under MD after 10 days and sharply decreased by $60 \%$ under ED after 30 days. Compared with GC, the response of NSCs, photosynthetic rate and biomass under ED were more dramatic than that under WL. The pool sizes of fructose and sucrose were larger under ED and WL, but the maximum pool size of starch occurred under the CG. The depletion of NSCs was not observed under ED at the end of the experiments in both 2015 and 2016.

Conclusions: Our results indicate that the dynamics of NSCs is an important physiological feature of plant adaptation and resistance to drought and waterlogging. In addition, high sugars concentrations are beneficial for the plants during the short-term extreme drought and the longer term mild drought or waterlogging.
\end{abstract}

Keywords: Carbon pool, Soil water, Whole-tree, Sugars, Starch, Tree mortality

\footnotetext{
*Correspondence: peng.changhui@uqam.ca

${ }^{1}$ Center for Ecological Forecasting and Global Change|, College of Forestry, Northwest A\&F University, Yangling 712100, Shaanxi, China

${ }^{2}$ Department of Biology Sciences, Institute of Environment Sciences, University of Quebec at Montreal, C.P. 8888, Succ. Center-Ville, Montreal H3C 3P8, Canada Full list of author information is available at the end of the article
} 


\section{Background}

Extreme event-induced tree mortality occurs globally and is likely to be exaggerated by future climate change, particularly drought and flood (Patz et al. 2005; Bréda et al. 2006; Huntington et al. 2006; Adams et al. 2009; Allen et al. 2010; Pachauri et al. 2014). As is well known, the events of extreme drought and floods will affect forest ecosystems along with rising temperatures, heat waves, and changing interactions between pests/pathogens and hosts (Bonan 2008; Allen et al. 2010). However, the underlying mechanisms of drought-induced tree mortality remain unclear (McDowell et al. 2008a, b; Sala 2009; Sala et al. 2010). In ideal condition over the time, tree mechanism is largely governed by the increasing stand level competition and social status on an individual tree (Saud et al. 2016, 2018), but under drought stress, trees are vulnerable to carbon starvation. Previous studies suggested that trees were vulnerable to carbon starvation under drought stress (Parker and Patton 1975; Bréda et al. 2006; McDowell et al. 2008a, b; Adams et al. 2009; Sala et al. 2010). However, there are the elusive and complex phenomena of nonstructural carbohydrates (NSCs) in plants in response to drought that are induced by different drought features (i.e., intensity and duration) and tree species, size, age and tissues (Sala et al. 2012; Hartmann et al. 2013; Palacio et al. 2014). Therefore, the lack of consensus among these studies on the effect of water availability on the NSC dynamics suggests that further studies are necessary to elucidate the underlying mechanisms (McDowell et al. 2008a, b; O'Grady et al. 2013).

Although studies on the effect of drought on NSCs is extensive, there has been few studies focusing on the effect of waterlogging (Board 2008; Parent et al. 2008; Nguyen et al. 2018). Sala et al. (2012) and Palacio et al. (2014) reported the manner in which we think about modeling tree growth and reviewed the literature on the minimum thresholds of nonstructural carbohydrates (NSC) under multiple environmental stresses. Some studies found that there was lack of direct evidence for the carbon-starvation hypothesis to explain water-induced mortality in plant (Sala 2009; Sala et al. 2010, 2012). Moreover, approximately $16 \%$ of land has been affected by waterlogging, resulting in severe economic losses (Luan et al. 2018). The assessment of the relationship between plant waterlogging and changes in NSCs concentration and allocation is very limited.

Some previous research suggested that different drought intensities induced different physiological responses of plants (Ditmarova et al. 2010; Osakabe et al. 2014) which may induce various NSC dynamics in trees to resist and survive under different water-stressed conditions (McDowell et al. 2008a, b). According to the previous hypothesis, mild drought stress may not result in the exhaustive depletion of NSCs, which may occur under severe drought stress, and trees may die from irreversible xylem cavitation (McDowell et al. 2011). However, there is a lack of research on the underlying mechanisms of NSC dynamics, particularly under drought (McDowell et al. 2008a, b) and waterlogging conditions.

In addition, not only drought intensity but also drought duration changes the NSC allocation and dynamics (McDowell et al. 2011). In the early stage of drought, the NSC concentrations may increase because the metabolic rate precedes the reduction in the photosynthetic rate (Korner 2003; Osakabe et al. 2014). However, as the drought stress persists, the reduction in the metabolic rate precedes that of the photosynthetic rate (Hsiao 1973; McDowell et al. 2011). Many previous studies focused only on the initial and final stage of the short-term drought manipulation (Regier et al. 2009, 2010; Anderegg and Anderegg 2013). Some previous studies also found that waterlogging as the dominant water stress within tree pits and thus avoidance of waterlogging conditions is required to stimulate increased tree growth (Grey et al. 2018; Ismail 2018). Therefore, it is necessary to understand how the duration of drought (McDowell and Sevanto 2010; Sala et al. 2010) and waterlogging (Sairam et al. 2008) changes the NSC dynamics in plants.

It has been demonstrated that different species have distinct functions and sizes of the NSC pool of different components (e.g., fructose, glucose, sucrose, starch, fructans and lipids) (Hoch et al. 2003; Würth et al. 2005; Millard et al. 2007; Palacio et al. 2014). Recently, there have been studies on the drought-induced allocations in carbon assimilation, transport, and utilization between the aboveand below-ground tree tissues (Day et al. 2008; Klein et al. 2016). However, the accurate estimate of the NSC dynamics in whole trees is difficult and challenging for mature trees, because it has been measured only by $C$ isotopes in a few studies (Ryan 2011; Dietze et al. 2014).

Therefore, it is necessary to study the response mechanisms of the NSC concentration of different tree species under drought and waterlogging stress with different intensities and durations. Robinia pseudoacacia (black locust) is a widely planted drought-resistant tree species in the Loess Plateau of China (Mantovani et al. 2014; Cao et al. 2018). It has unique features of rapid growth, drought resistance, resistance to barren soil and nitrogen fixation, and it can be used a model tree species to study the effect of water stress (drought and waterlogging) on tree growth and physiological acclimation. In this study, we manipulated different levels of the soil water content (ED: extreme drought, MD: mild drought, CG: control group, FC: field capacity and WL: waterlogging) and duration (10-day, 20-day and 30-day) to: 1) investigate the effect of drought intensity and duration on the NSC dynamics of $R$. pseudoacacia seedlings; and 2) examine the photosynthetic rate and plant growth to reveal the 
underlying mechanisms involved in NSC dynamics driven by drought and excessive water stresses. We hypothesized that 1) drought and waterlogging would significantly affect the NSC concentration, especially under ED condition; 2) a decrease in NSCs concentration would be observed at the later stage of the treatment, but not at the initial stage; and 3) plant NSCs respond more strongly to drought than to waterlogging.

\section{Methods}

\section{Experimental design}

We used a randomized block design with 4 replicates in 2015 and 2016, respectively. The NSC measurements were conducted on two-year old $R$. pseudoacacia L. seedlings grown in a greenhouse (located in the Northwest A\&F University, Yangling, Shaanxi, China) for two consecutive years, 2015 and 2016. Seventy-two seedlings were used in both years. The seedlings were grown in $30-\mathrm{cm}$ diameter and $40-\mathrm{cm}$ deep pots. Each pot contained a mixture of nutrient-poor sand and local field soil (Cumulic Anthrosol) with a ratio of 1:5. The local soil was sieved (4-mm sieve) to remove roots, coarse organic matter and coarse sand prior to mixing. We fertilized all the pots with one-quarter strength Hoagland solution after transplantation to the pots. The seedlings were grown for four and a half months prior to the beginning of the water stress treatments to minimize biases due to the difference in the initial weight and/or height of the seedlings.

The seedlings were grown in five different soil moisture regimes (Table 1), ranging from extreme drought (no watering, ED) to permanently waterlogged (WL) with interim stages at water-holding capacities of 30\% (MD), 70\% (CG) and field capacity (FC). We randomly assigned the seedlings to different treatments. All the treatments were started on August 1 in 2015 and 2016, and maintained for 30 days under ambient light conditions prior to the measurement of NSCs. Reflectometer probes (M002498, Theta Probe ML, Houston Texas USA) were used to monitor the moisture content, and the pots were watered whenever the water content varied by $>1 \%$ of the target level. The seedlings in the ED experiment underwent wilting, leaf yellowing and defoliation during the 30-day treatment; we did not harvest the seedlings but used the average soil water content (SWC) measured gravimetrically at the end of the experiment to deduce the overall water status of this treatment group (Table 1).

\section{Nonstructural carbohydrate measurements}

We measured NSCs with four randomly selected seedlings in both 2015 and 2016 prior to the start of the water treatments. NSC were measured at the end of the experiment on one randomly selected seedling from each water treatment from each block. The leaves, twigs, stems and roots were sampled separately for each seedling. The whole-seedling concentration and the pool of the TNSC is defined as the sum of the soluble sugars (including fructose, glucose and sucrose) and starch concentrations and pools, respectively.

The SS concentrations were measured using $1 \mathrm{~g}$ of dry biomass. SS was extracted using a warm $80 \%$ ethanol solution for $30 \mathrm{~min}$ and centrifuged at $5000 \times \mathrm{g}$ for $10 \mathrm{~min}$; this procedure was repeated 3 times. The supernatant (soluble sugars: fructose, glucose and sucrose, included) was analyzed for SS using an HPLC 1260 (Agilent 1260 Infinity LC, Burladingen, Germany) (Wilson et al. 1995; Raessler et al. 2010; Quentin et al. 2015). We extracted starch from the ethanol-insoluble residues after the ethanol was first removed by distillation extraction to measure SS. The starch in the residue was then released by boiling in $10 \mathrm{~mL}$ deionized water for $15 \mathrm{~min}$. After cooling to room temperature, $10 \mathrm{~mL} 9.2 \mathrm{M} \mathrm{HClO}_{4}$ was added, and the mixture was shaken for $15 \mathrm{~min}$. The mixture was centrifuged at $5000 \times \mathrm{g}$ for $10 \mathrm{~min}$. An additional extraction was conducted using $10 \mathrm{~mL} 4.6 \mathrm{M} \mathrm{HClO}_{4}$. The supernatant was retained, combined, and stored at $-20^{\circ} \mathrm{C}$ to determine the starch concentration based on the absorbance at $620 \mathrm{~nm}$ using a spectrophotometer (Yemn \& Willis, 1954; Kagan et al. 2014). The perchloric acid method was used to measure the starch. We calculated the whole-seedling NSC concentrations (C) using the following formula:

$$
\begin{aligned}
& C=\frac{C_{\mathrm{l}} \times m_{\mathrm{l}}+C_{\mathrm{t}} \times m_{\mathrm{t}}+C_{\mathrm{s}} \times m_{\mathrm{s}}+C_{\mathrm{r}} \times m_{\mathrm{r}}}{m_{\mathrm{l}}+m_{\mathrm{t}}+m_{\mathrm{s}}+m_{\mathrm{r}}} \\
& M_{\text {sampling }}=m_{\mathrm{l}}+m_{\mathrm{t}}+m_{\mathrm{s}}+m_{\mathrm{r}}
\end{aligned}
$$

where $C$ represents the whole-seedling NSC concentrations $\left(\mathrm{g} \cdot \mathrm{g}^{-1}\right), C_{\mathrm{l}}$ is the leaf NSC concentrations $\left(\mathrm{g} \cdot \mathrm{g}^{-1}\right)$, $m_{\mathrm{l}}$ is the mean leaf biomass $(\mathrm{g}), C_{\mathrm{t}}$ is the twig NSC concentrations $\left(\mathrm{g} \cdot \mathrm{g}^{-1}\right), m_{\mathrm{t}}$ is the mean twig biomass $(\mathrm{g}), C_{\mathrm{s}}$ is the stem NSC concentrations $\left(\mathrm{g} \cdot \mathrm{g}^{-1}\right), m_{\mathrm{s}}$ is the mean

Table 1 Effect of water status on gravimetric soil moisture across treatments, where Ext is extreme drought (no watering), MD and CG are at 30\% and 70\% of field capacity, FC is field capacity and WL is waterlogged

\begin{tabular}{llllll}
\hline Year & Ext & MD & CG & FC & \\
\hline 2015 & $(2.46 \pm 0.12) \%$ & $(7.23 \pm 0.13) \%$ & $(16.481 \pm 0.20) \%$ & $(24.02 \pm 0.23) \%$ & $(33.31 \pm 0.43) \%$ \\
2016 & $(2.70 \pm 0.16) \%$ & $(7.89 \pm 0.42) \%$ & $(16.85 \pm 0.18) \%$ & $(24.65 \pm 0.21) \%$ & $(33.96 \pm 0.41) \%$ \\
\hline
\end{tabular}

The values are means $\pm \mathrm{SE}$ 
stem biomass $(\mathrm{g}), C_{\mathrm{r}}$ is the root NSC concentrations $\left(\mathrm{g} \cdot \mathrm{g}^{-1}\right)$ and $m_{\mathrm{r}}$ is the mean root biomass (g). $M_{\text {sampling }}$ represents the whole-seedling biomass (g).

\section{Soil moisture and seedling biomass}

The gravimetric soil water content was determined on a 20-g sample of sieved (2-mm mesh) and homogenized soil from each pot by oven drying at $105^{\circ} \mathrm{C}$ for $24 \mathrm{~h}$. We determined the biomass of the leaves, twigs, stems and roots separately for all seedlings. The materials were oven-dried for $48 \mathrm{~h}$ at $70^{\circ} \mathrm{C}$ in kraft bags $(12 \mathrm{~cm} \times 15 \mathrm{~cm})$ to a constant weight and then weighed.

\section{Statistical analysis}

A one-way analysis of variance (ANOVA) was used to examine the relationship between the SWC and dependent variables among the water treatments at the time of harvest. The data normality and homogeneity of variance were tested using the Shapiro-Wilk and Levene tests, respectively. We also tested the concentrations and pools of NSCs (soluble sugars, fructose, glucose, sucrose and starch) in each seedling for normality. In addition, we used a two-way ANOVA with a water treatment as a fixed factor and a block as a random factor to test the difference in SS and starch among the water treatments. The total seedling biomass as a covariate to account was included to scale the relationships between the plant size and response variables (Minucci et al. 2017). The familywise type I error rate for contrasts was controlled at $a=0.05$ using a Bonferroni correction. If there was no interaction, a post hoc separation of means was conducted using Tukey's honestly significant difference (HSD) test. We also used a repeated-measures analysis of variance (ANOVA) to determine the effects of the soil water stresses (ED, MD, CG, FC and WL) and treatment durations (0-day, 10-day, 20-day and 30-day) on the net photosynthetic rates, dry biomass and the TNSC (soluble sugars $=$ fructose + glucose + sucrose; starch) concentrations in each tissue. The assumption of sphericity was tested using Mauchly's sphericity test (Mauchly 1940). The Bonferroni test was used to identify significant differences in the mean net photosynthetic rates, dry biomass, and NSCs concentrations in each tissue. The results were considered significant when $P<0.05$. All statistical analyses were performed using SPSS v.20.0 (SPSS, Inc., Chicago, USA).

\section{Results}

The effect of drought intensity, waterlogging and duration on the photosynthetic rate and biomass

The effects of water stress (i.e., both soil water content and treatment duration) on net photosynthetic rates and biomass were all significant $(P<0.01$; Figs. 1 and 2, Table $1)$. The repeated measures ANOVA indicated that the changes in the net photosynthetic rate under ED, MD and WL over time were significant $(P<0.01$; Fig. $1 \mathrm{a}$ and $\mathrm{b})$. The lowest values of the photosynthetic rate under FC and WL were observed on the first sampling (10-day).

The biomass under the drought stresses (i.e., ED and $\mathrm{MD}$ ) decreased by $56 \%$ and $23 \%$ under ED and MD, respectively, compared to the initial value (0-day) (Fig. 2a and $\mathrm{b})$. The biomass under ED decreased consistently over the course of experiment $(P<0.01)$ whereas it showed an opposite trend under CG. Under WL, the biomass first decreased and then increased with time.

\section{The TNSC and SS concentrations in whole seedlings}

The effects of both soil water intensity and duration on the concentrations of TNSC and SS were all significant $(P<0.01$; Fig. 3$)$, except for MD and CG. The results of repeated measures ANOVA showed that the changes in the TNSC and soluble sugar concentrations under ED, FC and WL over time were significant $(P<0.01$; Fig. 3a-d). The maximum of TNSC and SS under ED, $\mathrm{MD}, \mathrm{FC}$ and $\mathrm{WL}$ were observed on the first sampling (10-day). However, the increments of the concentration of TNSC and SS under ED and MD in the first sampling were much higher than those under FC and WL. Compared to CG, the TNSC concentration under ED, MD, FC and WL increased by $114.8 \%, 68.9 \%, 21.8 \%$ and $48.8 \%$ on 10 -day, respectively. Compared to CG, the SS concentration under ED, MD, FC and WL increased by $207.2 \%, 136.6 \%, 64.5 \%$ and $105.7 \%$ on 10 -day, respectively. After the second (20-day) and third (30-day) sampling, the TNSC and SS concentrations were rapidly reduced under ED and slightly reduced under FC and WL compared to CG. Under MD treatment, the TNSC and SS concentrations kept relatively stable after their increase.

\section{The concentrations of NSC components (fructose, glucose, sucrose and starch)}

Both the soil water treatment intensity and duration significantly influenced the starch concentrations in seedlings $(P<0.01$; Fig. 4). Under the CG treatment, the starch concentrations gradually increased with time, and the highest concentrations were observed at the end of the experiment in both years. Under the MD, FC and WL treatments, the starch concentrations showed similar patterns with significant variation $(P<0.01$; Fig. $4 \mathrm{~g}$ and $h)$. The starch concentration under ED significantly decreased over time. The starch concentration was the highest under the CG treatment in all three sampling periods, and the lowest concentrations were found in ED (Fig. $4 \mathrm{~g}$ and $\mathrm{h}$ ). During the experimental period, the starch concentrations in the seedlings under the ED, $\mathrm{MD}, \mathrm{FC}$ and WL treatments were significantly decreased at the three samplings, while that under the CG treatment was significantly increased compared to the initial 

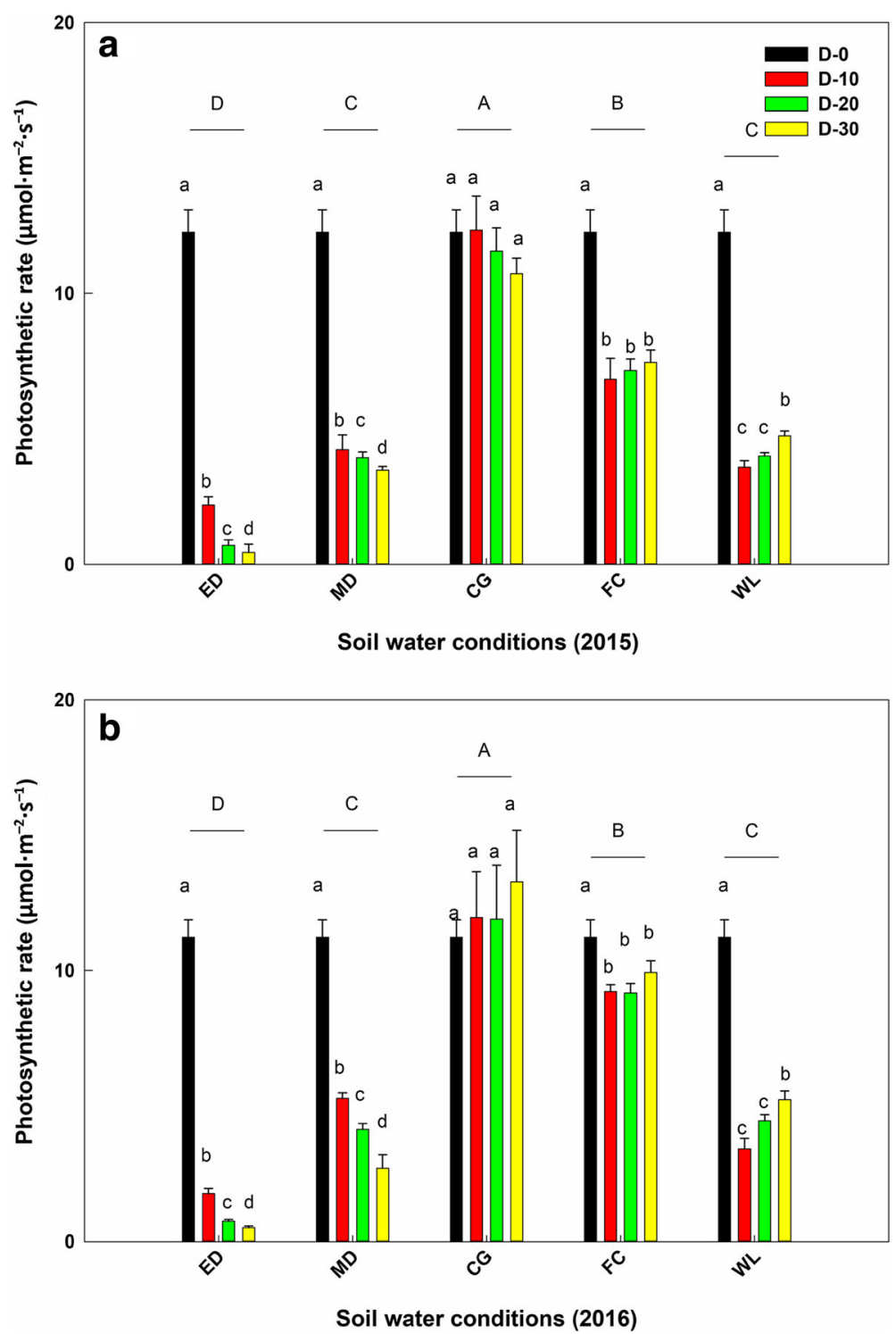

Fig. 1 Dynamics in the net photosynthetic rate $\left(A_{n}\right)$. The plot shows $A_{n}$ at the beginning of the experiments (initial, 0-day, black bar), first sampling (10-day, red bar), second sampling (20-day, green bar) and at the end of the 30-day (third sampling, yellow bar) water status treatments in 2015 (a) and 2016 (b) on the whole seedling level. The treatments are ED: extreme drought, MD: 30\% of the field capacity (FC), CG: 70\% of the field capacity, FC: field capacity and WL: permanently waterlogged. Values are back-transformed averages and error bars represent 95\% confidence intervals. Note that the upper-case letter refers to the significant differences among treatments and the lower-case letter refers to the significant differences within-subject

$(P<0.01$; Fig. 4g and h). Under ED, FC and WL, similar patterns of variation were observed between the fructose and sucrose concentrations that peaked at the first sampling and decreased with time thereafter. Under MD, the fructose and sucrose concentrations were maintained at a high level, and they were smaller than that under ED but larger than the rest of the treatments. (Fig. $4 a, b$, e and f). The glucose concentrations under all the treatments were much lower than that of the fructose and sucrose. However, the glucose concentrations significantly increased under the $\mathrm{ED}, \mathrm{MD}, \mathrm{FC}$ and $\mathrm{WL}$ treatments compared to CG $(P<0.01$; Fig. $4 \mathrm{c}$ and d). Compared to $C G$, the increased amplitude of the glucose concentration under FC and WL was smaller than those under ED and MD. The glucose concentrations under the CG were the lowest among the measurements (Fig. $4 \mathrm{c}$ and d).

The ratios of soluble sugars and starch in the seedlings The effects of the soil water treatment intensity and duration on the ratios of soluble sugars to starch (RSS) in the seedlings were significant in both years $(P<0.01$; Fig. 5), except for CG and FC. Similar variation in the 

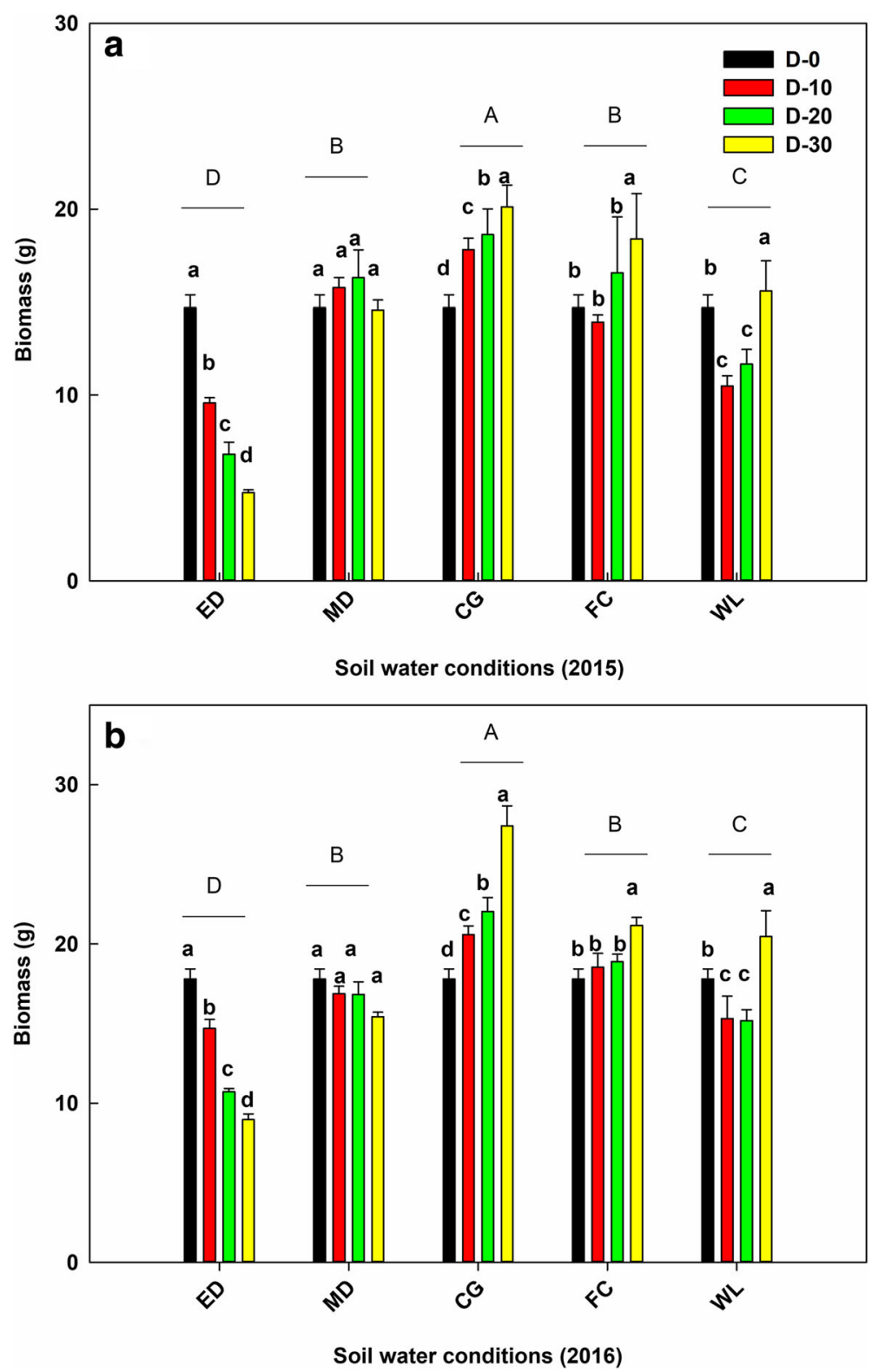

Fig. 2 Dynamics in dry biomass. The plot shows that biomass at the beginning of the experiments (initial, 0-day, black bar), first sampling (10-day, red bar), second sampling (20-day, green bar) and at the end of the experiments (third sampling, 30-day, yellow bar) water status treatments in 2015 (a) and 2016 (b) on the whole seedling level. The treatments are ED: extreme drought, MD: 30\% of the field capacity (FC), CG: 70\% of the field capacity, FC: field capacity and WL: permanently waterlogged. Values are the back-transformed averages, and the error bars represent 95\% confidence intervals. Note that the upper-case letter refers to the significant differences among treatments and the lower-case letter refers to the significant differences within-subject

patterns of the ratios of the soluble sugars to starch was found between MD and WL, under which the ratios tended to increase over time. Under the CG treatment, the ratio tended to decrease at 10-day ( $P<0.01$; Fig. $5 \mathrm{a}$ and b). Except for the ratios of the sampling on 30-day, the ratios were significantly higher under ED than those under all the other treatments $(P<0.01$; Fig. $5 \mathrm{a}$ and b). However, in each treatment, the ratios were significantly higher under ED, MD, FC and WL than that under the CG treatment $(P<0.01)$.
The ratios of above- and below-ground in NSC, SS and starch pools of seedlings

The effects of the soil water treatment intensity and duration on the ratios of above- and below-ground TNSC, soluble sugars and starch (RAB) of seedlings were significant in both years $(P<0.01$; Fig. 6a-f). Similar variations in the patterns of the RAB ratios of the TNSC and soluble sugars were found across treatments. The ratios tended to be decreased under the high soil water 


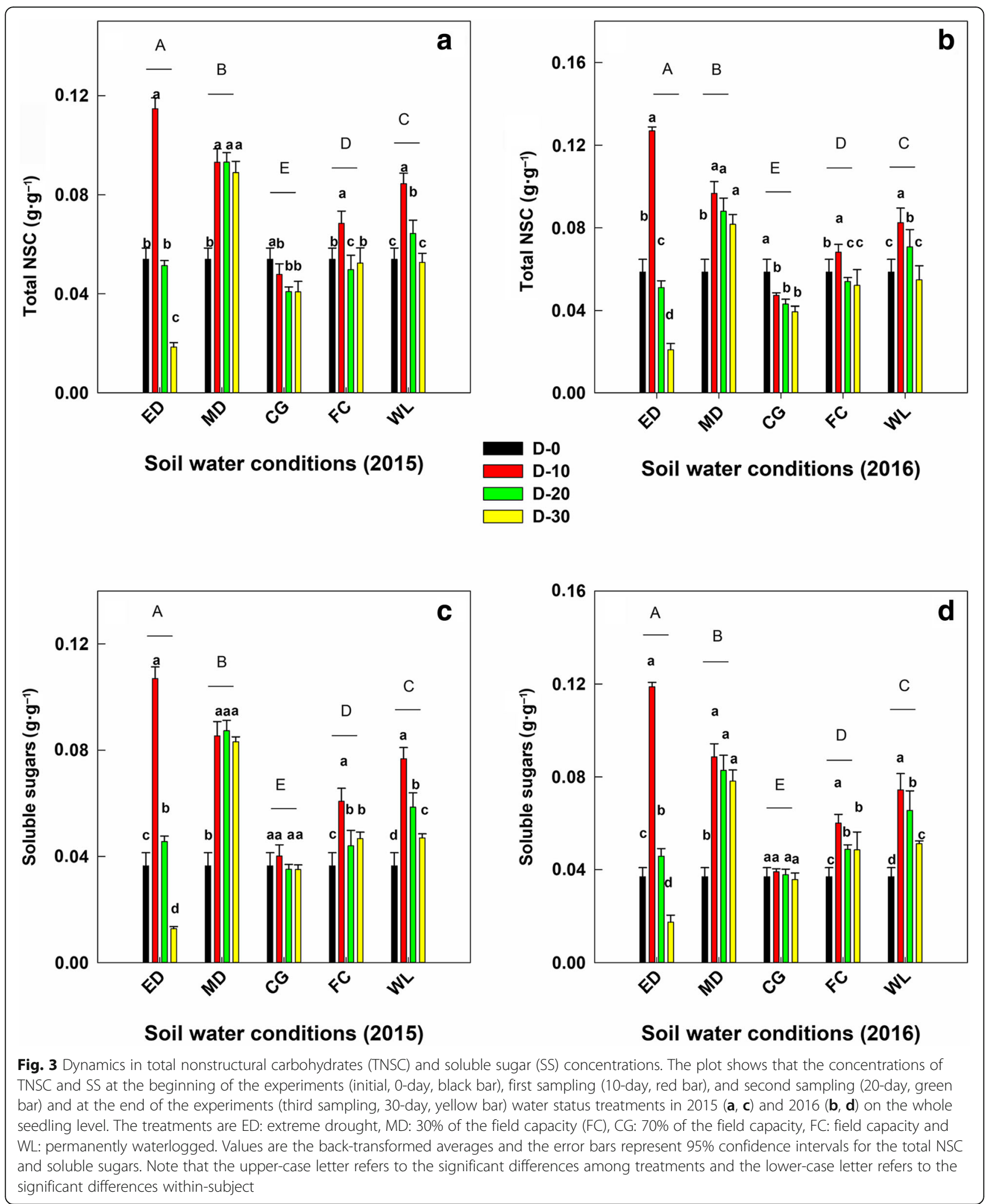

treatments (FC and WL) over time, but increasing trend of RAB was observed under FC on 30-day $(P<0.01$; Fig. 6a-d). Under the CG, the RABs of TNSC and SS tended to increase stably. However, for each treatment, the RABs were significantly higher under CG and FC than that under the ED, MD and WL treatments $(P<0.01)$. 

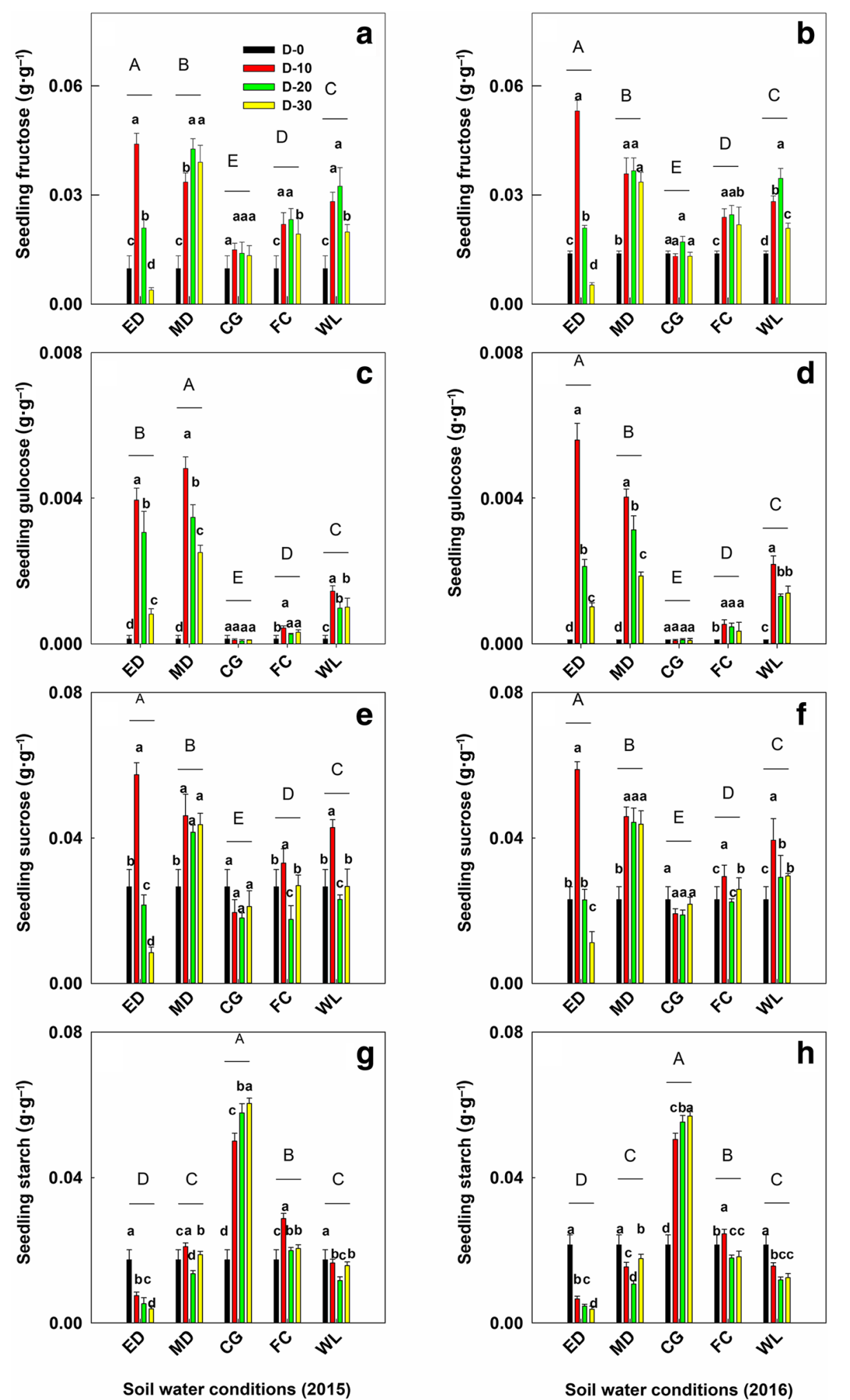

Fig. 4 (See legend on next page.) 
(See figure on previous page.)

Fig. 4 Dynamics in the concentrations of fructose, glucose, sucrose and starch. The concentrations at the beginning of the experiments (initial, 0-day, black bar), first sampling (10-day, red bar), second sampling (20-day, green bar) and at the end of the experiments (third sampling, 30-day, yellow bar) water status treatments on the whole seedling level in 2015 (a, c, e and $\mathbf{g}$ ) and 2016 (b, d, f and $\mathbf{h}$ ). The treatments are ED: extreme drought, MD: $30 \%$ of the field capacity (FC), W70: 70\% of the field capacity, FC: field capacity and WL: permanently waterlogged. Values are backtransformed averages, and the error bars represent $95 \%$ confidence intervals for fructose and glucose. Note that the upper-case letter refers to the significant differences among treatments and the lower-case letter refers to the significant differences within-subject

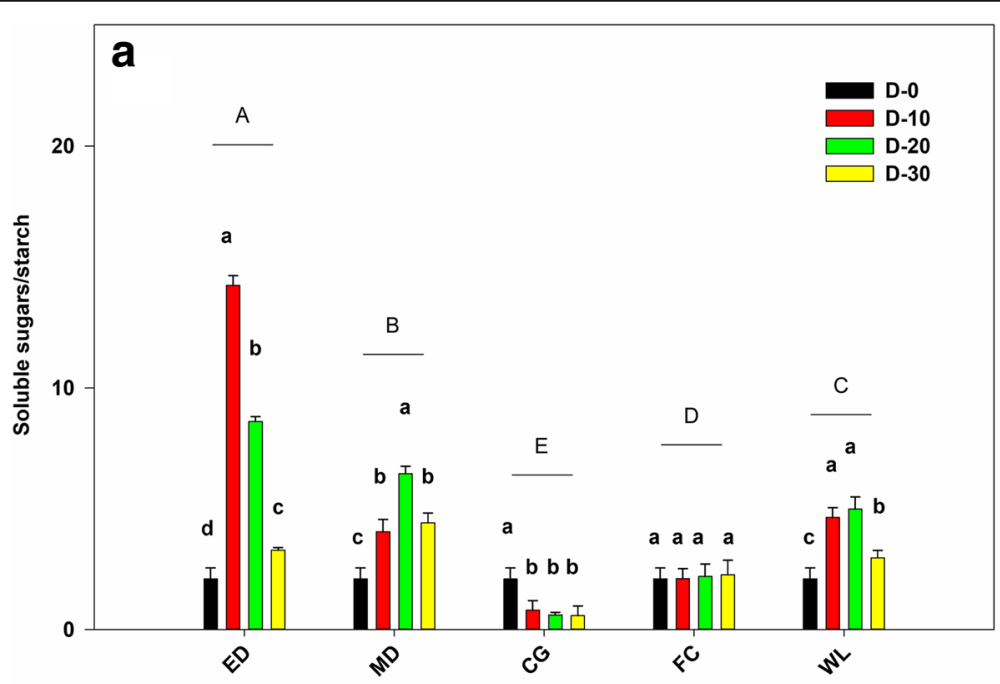

Soil water conditions (2015)

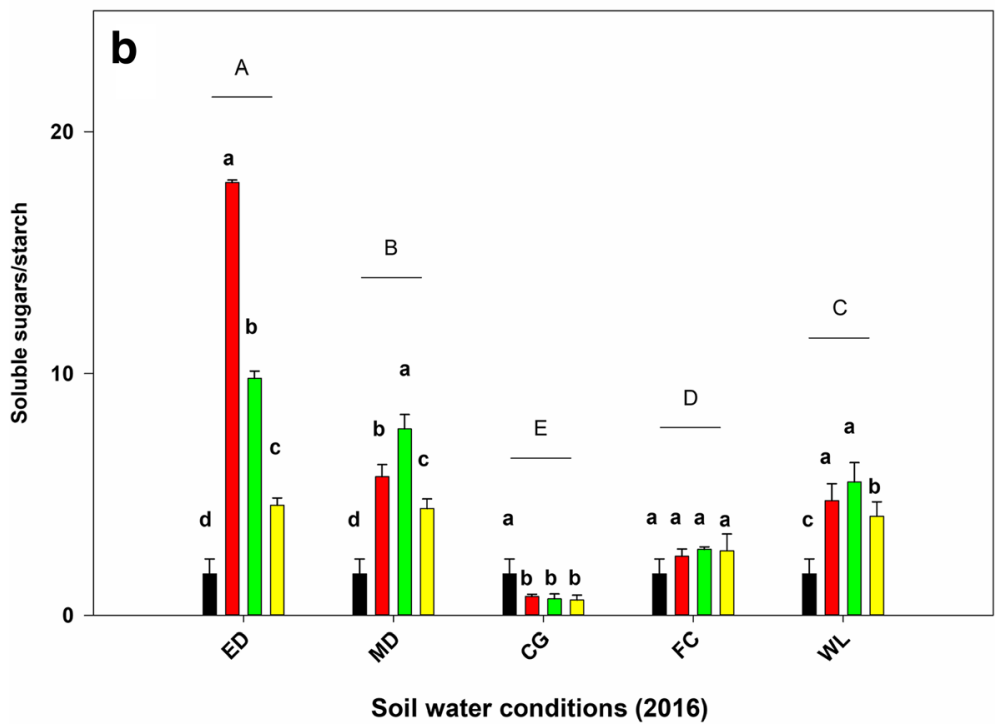

Fig. 5 Dynamics in the ratio of soluble sugars and starch (RSS). The plot shows that RSS at the beginning of the experiments (initial, 0-day, black bar), first sampling (10-day, red bar), second sampling (20-day, green bar) and at the end of the experiments (third sampling, 30-day, yellow bar) water status treatments in 2015 (a) and 2016 (b) on the whole seedling level. The treatments are ED: extreme drought, MD: 30\% of the field capacity (FC), W70: 70\% of the field capacity, FC: field capacity and WL: permanently waterlogged. Values are back-transformed averages and error bars represent $95 \%$ confidence intervals. Note that the upper-case letter refers to the significant differences among treatments and the lower-case letter refers to the significant differences within-subject 

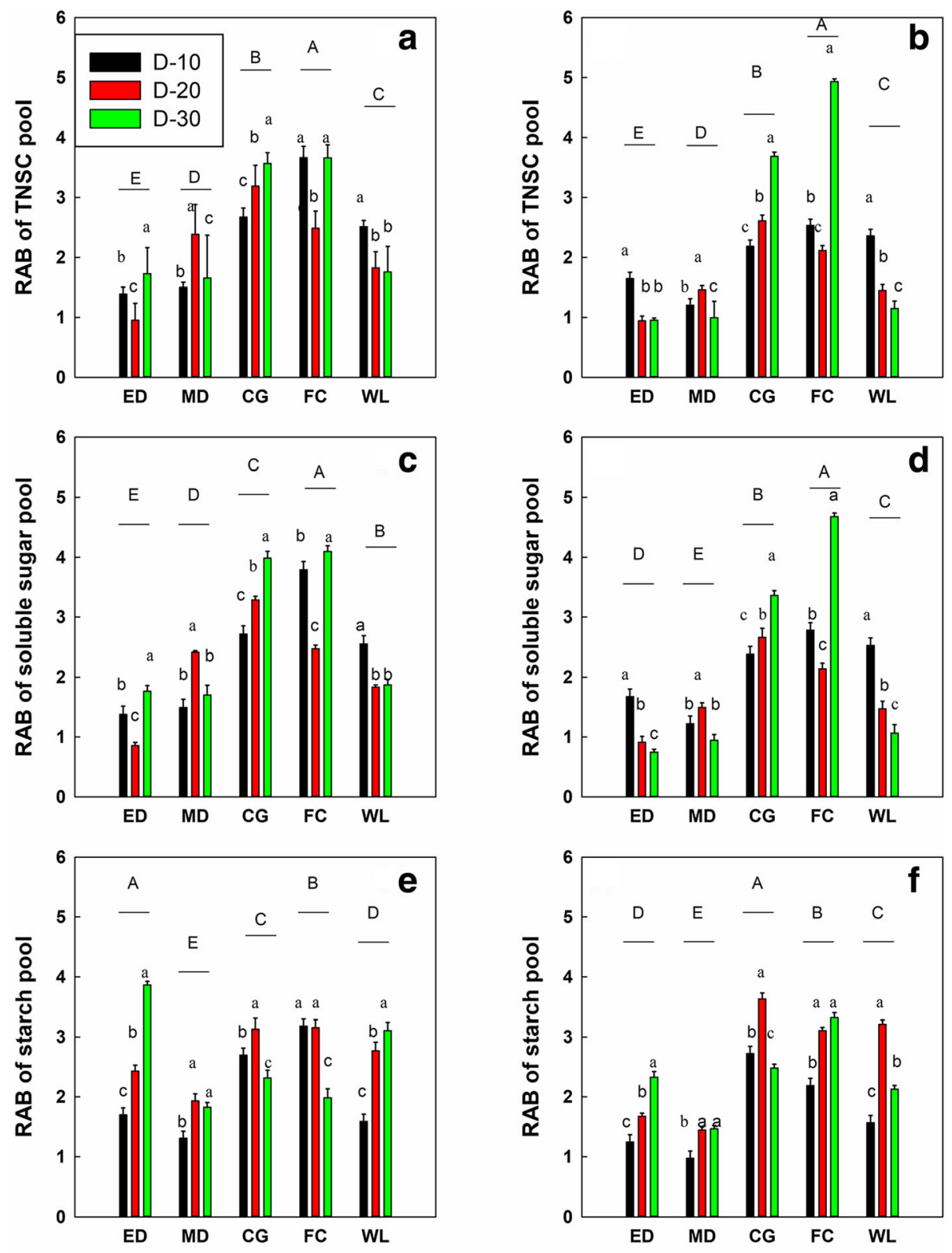

Soil water conditions (2015)

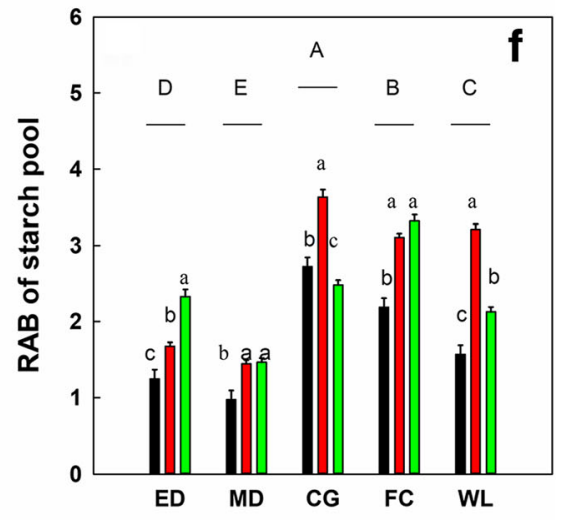

Soil water conditions (2016)

Fig. 6 Dynamics in the ratios of above- and below-ground (RAB) of TNSC, SS and starch. The plot shows that RAB at the first sampling of the experiments (10-day, black bar), second sampling (20-day, red bar) and at the end of the experiments (third sampling, 30-day, green bar) water status treatments in 2015 (a, c and e) and 2016 (b, d and f). The treatments are ED: extreme drought, MD: 30\% of the field capacity (FC), W70: $70 \%$ of the field capacity, FC: field capacity and WL: permanently waterlogged. Values are back-transformed averages and error bars represent $95 \%$ confidence intervals. Note that the upper-case letter refers to the significant differences among treatments and the lower-case letter refers to the significant differences within-subject

\section{Discussions}

Effects of the treatment intensities on the total non-structural carbohydrates dynamics

We found that the NSC concentrations under extreme drought (ED) were significantly lower than those under the control group (CG) and high soil water conditions (FC and WL, included) at 20-day and 30-day. These results support our first hypothesis that drought stress would significantly influence the NSC concentration, particularly under ED at the initial stage of the treatments (10-day), which is consistent with recent findings (Zhang et al. 2015; Cao et al. 2018). However, their studies did not investigate different NSC components (fructose, glucose and sucrose) of soluble sugars. In 
contrast, waterlogging only had moderate legacy effects on the NSC concentrations and pools, and subsequently plant growth and productivity were not significantly affected. Even some historic studies showed that higher initial NSC pools were not advantageous for resistance and survival in plants (Pretzsch et al. 2018). But we observed that bigger NSC pool sizes play a key role under drought and waterlogging conditions during short-term.

\section{Effects of the treatment intensities on the soluble sugars dynamics}

It is important to note that soluble sugars play a crucial role in osmotic adjustment, vascular transport, and the repair of embolisms (Sala et al. 2012). The increase in soluble sugar concentrations has been reported in several previous studies (Latt et al. 2001; Silva et al. 2010). Increased concentrations of soluble sugars can remit the tree water potential, maintain cell turgor, and enhance water absorption by the roots from the soil (Handa et al. 1983; Silva et al. 2010; Williams et al. 2012). However, under drought conditions, our results were generally consistent with the previous findings that leaves can save carbon and directly make carbon available for plant growth (Kozlowski 1992; McDowell et al. 2008a, b; Dietze et al. 2014). In addition, the previous results suggested that plants used less and stored greater NSC, particularly conifer species (Michelot et al. 2012; Thomas and Martin 2012). However, a previous study found that broadleaf deciduous seedlings primarily contain more NSC in the roots than that at the whole-seedling level (Villar-Salvador et al. 1999, 2015). Other studies showed that there were no significant differences in the NSC concentrations between tree species (Hoch et al. 2003; Zhang et al. 2014). Our results are consistent with the generally accepted observation that higher NSC concentrations occurred under drought and high soil water conditions (FC and WL) compared to normal moisture conditions (Zhang et al. 2014, 2015; Cao et al. 2018). Our results were also consistent with those of the previous studies showing that the starch and soluble sugars have a transformational relationship under ambient pressure. This is mainly due to the reduction of temporarily stored starch in plants to compensate for the reduction of carbon assimilation and the maintenance of respiration and survival required for net photosynthesis from leaves. In particular, starch reaches a minimum during extreme environmental stresses (Chantuma et al. 2009; Li et al. 2013a, b). The reduction in biomass could be due to limitations in growth, structural carbon degradation and tissues (leaves and twigs) drop. In addition, the features of starch in plants facilitate its use as a long-term and accessible carbon storage, while soluble sugars act as an intermediate, ready-to-use energy and structure for growth and to resist stresses under biotic and abiotic conditions (Würth et al. 2005; Richardson et al. 2013; Bellasio et al. 2014; Richardson et al. 2015).

\section{Effects of the treatment intensities on fructose, glucose and sucrose dynamics}

Our results on the concentration of the SS components showed that there were similar patterns of variation in the TNSC and SS under drought stresses. However, the glucose concentration has the lowest value among the three components of SS. Maybe because glucose is involved in some biochemical synthetic processes and masked in the form of other compounds. Glucose has hormone-like functions and controls many vital processes through mostly unknown mechanisms in plants, may be more sensitive to stress signals (Cheng et al. 2002; León and Sheen 2003; Sheen 2014). The patterns of fructose and sucrose are consistent with recent studies (Li et al. 2011; Tauzin and Giardina 2014). In living plants, soluble sugars not only provide energy and carbon skeletons but also serve as signaling molecules to adapt to environmental stresses. Information on plant glucose and sucrose signaling is available, but to date, no fructose-specific signaling pathway has been reported ( $\mathrm{Li}$ et al. 2011). In our study, fructose patterns were similar to those of sucrose. We could also conclude that fructose participated in signal and osmotic adjustments, although the results showed that the glucose variation trends were the most sensitive, especially under ED and MD.

\section{Similarities and differences between drought and high soil moisture}

In addition, drought stress led to an increased NSC concentration more significantly than those under field capacity (FC) and waterlogged (WL) across the experiments in both 2015 and 2016. Differences among the effects of soil moisture intensity on the NSC concentrations may result from the changes in the carbon source or sink and the underlying carbon allocation mechanisms. Some historical studies have found that under carbon source limited conditions (from photosynthesis), plants can increase their NSC storage and allocate it to survive at the expense of regular growth (Pantin et al. 2013; Wiley 2013; Saffell et al. 2014). In addition, Wiley (2013) found that trees can maintain higher NSC levels to survive with lower growth under moderate drought, while plants under severe drought (ED) had significantly lower NSC at the end of the experiments. In our study, net photosynthetic rates have been decreasing along with the drought and exceed-CG (FC and WL) stress gradients (Fig. 1a and b). As a result, the NSC concentrations under $\mathrm{MD}$ and $\mathrm{WL}$ were slightly higher than those under the CG, while NSCs under ED were significantly higher at the first sampling and lower than those under the CG at the second and third sampling (Fatichi et al. 
2014). In addition, the synthesis of starch under ED and MD stress were inhibited to a greater extent than those under WL and FC, and the activity of hydrolases is sharply activated, leading to an increase in the ratio of soluble sugars to starch. Latt et al. (2001) reported the conversion of starch to sugars in all the tissues of the trees under drought stress. In our study, an increase in the concentration of soluble sugars and the ratios of soluble sugars to starch was also observed under all drought stresses (ED and MD). Silva et al. (2010) proposed that $\mathrm{K}^{+}$and $\mathrm{Na}^{+}$play crucial roles in osmotic adjustment under normal soil water conditions, while soluble sugars are more important under relatively stressful conditions, which may be due to the effects of hydraulic limitations that emerged earlier than carbon starvation (Adams et al. 2017). These results suggest that the $R$. pseudoacacia seedlings can adjust the osmotic potential through different pathways under drought and high soil moisture, because $R$. pseudoacacia could increase sugar concentrations to mitigate the increasing drought stress under ED and MD.

Under high soil water conditions (FC and WL), our results showed that the TNSC and SS were also increased, with slight fluctuations, but to a lesser degree than those under ED and MD. Waterlogging stops root growth and function because of the oxygen shortages that restrict root respiration. The concentrations of potentially toxic compounds increase in anoxic soils, which can enter through roots, damaging both root and above-ground tissues. Plants have some potential defense mechanisms to buffer waterlogging stresses through germinating aerial roots to survive. Hartmann et al. $(2013,2015)$ conducted experiments examining high soil water mechanisms and reported on those on conifers (Hartmann et al. 2013, 2015; Hartmann and Trumbore 2016). They found that carbon metabolism below-ground is related to the mechanism of tree mortality. Our results on fructose, glucose and sucrose showed that there were similar patterns of variation with the TNSC and SS, except for the lowest concentration of glucose. The whole process was observed, especially under drought conditions.

\section{Effects of treatment duration on the NSCs dynamics}

All the total non-structural carbohydrates (NSCs) concentration and dynamics of Robinia pseudoacacia L. seedlings under drought treatments were basically consistent but vary with different soil water treatments from the beginning to the final sampling. However, the NSC concentrations under ED decreased from 10-day to 30-day. In contrast, under MD, they significantly and stably increased over the course of the experiments in both 2015 and 2016. In addition, the net photosynthetic rate and biomass were significantly and synchronously decreased under ED, MD and WL but increased at 20-day under WL (see Figs. 2 and 3). Therefore, the carbon assimilation was reduced except for the middle and late period of WL in 2015 and 2016. These results support our second hypothesis that a decrease in NSCs would be observed when the drought period was longer but not during the initial drought phase. In addition, we observed that the concentrations of the TNSC, as well as the soluble sugars, were significantly greater at the 10-day than that at the 20-day and 30-day sampling times. However, previous research showed that there were similar results for red oak but the opposite results for white pine (coniferous species) (Richardson et al. 2015). Therefore, species type, plant tissues, sampling time and the protocol of the selection of sampling trees may be attributed to the discrepancy in these results (Dietze and Moorcroft 2011; Zhang et al. 2014). The NSC concentrations (TNSC, SS, fructose, glucose and sucrose) in most plants increased with decreased precipitation (Korner 2003; Würth et al. 2005), which is supported for our results and primarily due to the increased soluble sugars produced by starch degradation under drought conditions (Fig. 5). Waterlogging and the subsequent oxygen stress can lead to detrimental growth effects as it induces important physiological responses by plants and changes the nonstructural carbohydrates allocation in seedlings. Previous studies showed that stomata conductance and hydraulic conductivity are diminished under waterlogging (Vartapetian and Jackson 1997; Parent et al. 2008) and often a reduction in the rate of photosynthesis can be observed (Dreyer 1994; Pezeshki and DeLaune 1996). Metabolism in roots changes from aerobic (mitochondrial) respiration to anaerobic fermentation, leading to a depletion of carbohydrate reserves (Parent et al. 2008). However, the depletion of carbohydrate reserves was not observed in our studies, maybe due to the treatment durations were too short to be observed, and maybe mainly due to germinate some aerial roots at 20-day, so that once again unclogged the NSC pathways. As a consequence of these disturbances of vital physiological and metabolic processes, reductions of above-ground growth and main root growth are commonly observed in woody plants subjected to soil waterlogging condition (Frye and Grosse 1992; Kozlowski and Pallardy 2002; Glenz et al. 2006).

\section{Effects of treatment intensity and duration on the NSCs dynamics}

Previous studies have shown that the dynamics of NSCs in drought vary considerably among species and with the duration and intensity of the stress (Adams et al. 2009; McDowell et al. 2011). When converted into the ratio of soluble sugars to starch (RSS), the dynamics of the RSS differed significantly at four time sampling $(P<0.01$, Fig. 5), due to variation among the replicates and 
microenvironments, and significant differences were noted among the treatments (Additional file 1: Figures S1 and S2). These phenomena can help to understanding of the interpretation of starch conversion into soluble sugars in plants to provide energy and regulate the osmotic potential to alleviate and resist drought and waterlogging over the short-term. Our results are partially consistent with the previous experiments in which herbaceous plants, short-lived with respect to woody plants, show constant or increased carbon storage during drought, very likely because of reduced translocation (Müller et al. 2001). The increase in the carbon storage pool and concentration also reflects the role of soluble sugars in osmoregulation and reactive oxygen species (ROS) regulation, both of which lead to basal alkalization, which destroys membrane function (Miller et al. 2008). However, photosynthesis was lower for longer duration than the initial stage, demonstrating that factors in addition to the negative carbon balance trigger plant carbohydrate metabolism (McDowell et al. 2008a, b; Adams et al. 2009, 2013; Sevanto et al. 2014).

Previous research has indicated that the timescale of various physiological processes during different drought stages plays an important role in understanding the NSC dynamics (Fatichi et al. 2014). In the short term, adaptation to the lag in photosynthesis may lead to the accumulation of starch and soluble sugars (Hsiao 1973; Korner 2003). In the medium term, the decline in photosynthesis before respiration can reduce the storage of NSCs due to their metabolism (Hsiao 1973; McDowell et al. 2011; Beier et al. 2012). In the long term, complex domestication mechanisms may be used to fine-tune tree growth via photosynthesis in order to ensure the storage of NSC (Kozlowski 1992; Hoch et al. 2003; Fatichi et al. 2014). However, the consumption of NSCs occurs under conditions in which trees cannot grow in harmony with photosynthesis (McDowell et al. 2008a, b). In our study, we observed higher NSC concentrations under both drought and waterlogging stress compared to those under the field capacity (FC), suggesting that the time frame of $30 \mathrm{~d}$ (from the initiation of soil water treatment to the third time sampling) was long enough for the downregulation of photosynthesis. The lower, but continuous, increase in the NSC concentrations under $\mathrm{MD}$ and ED from the beginning to the end might be the result of the acclimation mechanisms that allowed the seedlings to adjust the balance of carbon sink and source, preventing NSC depletion and sustaining survival and reserve accumulation under drought stress (Scartazza et al. 2013). The significant decrease in the NSC concentrations in the leaves, twigs and stems during the growing season under ED at the end of the experiment may result from the poor adjustment of growth, photosynthesis, and translocation of NSCs to metabolism. At the end of the two-year experiments, as the net photosynthetic rates under ED and MD significantly decreased, the seedlings under the CG maintained relatively sufficient NSC supplies by decreasing their soluble sugar storage and may increase starch reserves, while the seedlings under ED, whose growth have decreased or even stopped prior to this period, consumed NSCs to maintain normal metabolism.

Additionally, NSCs play fundamental roles in plant germination, growth, reproduction, and resistance and may also be conclusive to plant survival under negative stresses (Kozlowski 1992). In particular, NSCs are mobilized in trees to maintain respiration during stress, build biomass and sustain new growth in the future and supply energy for any adaptive responses to drought (Kozlowski 1992; Barbaroux et al. 2003). As is well known, $R$. pseudoacacia is an annular porous and Leguminosae species that needs to obtain new leaf reserves before germination to reach a large part of its annual stem growth (Bréda and Granier 1996; Landhäusser and Lieffers 2011). Annular porous species have a higher respiratory capacity than diffuse porous species (Barbaroux and Breda 2002; Barbaroux et al. 2003), and there are higher basal respiration rates and Q10 values in the plants (Edwards and Hanson 1996). Therefore, $R$ pseudoacacia requires a larger amount of NSC under drought conditions than those under high moisture conditions, which is supported by our study in which the NSC concentrations decreased significantly under ED at the end of the two-year experiments. In addition, the RSS in the seedlings would continue to decrease from 0 -day to 30-day but would still be higher than the initial value as well as the value of the control (CG) over time. If the starch is consumed in large quantities, it indicates that the plant needs soluble sugars to resist the stress. However, even under the ED conditions, the starch and soluble sugars were not exhausted at 30 days. Consequently, $R$. pseudoacacia seedlings under ED may be more vulnerable to high temperature and other biotic stresses during the experiments. Therefore, it would require additional study to explore the impact of high temperature on the variation of NSCs under drought and waterlogging conditions (Galvez et al. 2013). However, there are still several limitations in this study: 1) We studied the mechanisms of NSC dynamic changes under continuous drought and waterlogging conditions but did not clearly define the tipping point of NSCs for tree mortality, which used membrane failure and chlorophyll fluorescence to predict the plant mortality under drought (Guadagno et al. 2017); 2) We primarily studied the partitioning and dynamics of the TNSC, SS, starch, fructose, glucose and sucrose concentrations on the whole-tree scale. The change status did not use isotope techniques to accurately reveal the NSC allocation 
mechanisms; 3) we measured photosynthesis and biomass as covariates to clarify the NSC dynamic mechanisms without combining hydraulic characteristics. We should combine carbon starvation with hydraulic failure to explore the response of the trees to drought and waterlogging to understand possible mechanisms, and further research on this direction is urgently needed.

\section{Conclusions}

The main conclusions of this study are as follows: 1) the intensity and duration of soil water stress have significant effects on the NSC dynamics of Robinia pseudoacacia seedlings. 2) We observed a significant decrease in NSC concentration under severe drought stress, and the NSC concentration under MD and FC remained high levels. The NSC concentration under WL conditions recovered near the initial value. 3) Drought causes seedlings to preferentially increase NSC in below-ground tissues. While FC and WL can promote the distribution of NSCs mainly in the above-ground tissues. In summary, the dynamic characteristics (for strength and duration) and component types of NSCs in drought and waterlogged are important for elucidating the relationship between NSC dynamics and soil water stress. However, further research is needed to investigate the NSC dynamics during the dormant season, as well as the NSC allocation and storage characteristics of plant tissues under drought and waterlogging stress.

\section{Additional file}

Additional file 1: Figure S1. Air temperature. Figure S2. Air humidity (DOCX 113kb)

\section{Abbreviations}

$A_{n}$ : The net photosynthetic rate; ANOVA: Analysis of variance; CG: Control group; ED: Extreme drought; FC: Field capacity; Frc: Fructose; Glc: Glucose; HSWT: High soil water treatment (including field capacity and waterlogging); MD: Moderate drought; RAB: The ratios of above- and below-ground; ROS: Reactive oxygen species; RSS: The ratio of soluble sugars and starch; SS: Soluble sugars; Sta: Starch; Suc: Sucrose; TNSC: Total nonstructural carbohydrates; WL: Waterlogging

\section{Acknowledgements}

We greatly appreciate the help of Dr. Yi Zhang on the implementation of our experiments and seedling culture and water control in the greenhouse.

\footnotetext{
Funding

This study was mainly funded by the National Key R\&D Program of China (2016YFC0500203), Qian Ren program and the Natural Sciences and Engineering Research Council of Canada (NSERC) Discovery Grant. The National Natural Science Foundation of China (41571081) and the National Key R\&D Program of China (2016YFC0501804). The National Natural Science Foundation of China (41601098) and the Young Excellence Program for the Teachers of the College of Forestry, Northwest A\&F University (Z111021603).
}

\section{Availability of data and materials}

The datasets used and/or analyzed during the current study are available from the corresponding author on reasonable request.
Compliance with ethical standards

Not applicable

\section{Authors' contributions}

$\mathrm{BY}, \mathrm{CP}$ and MW contributed conception and design of the study; BY organized the database; BY performed the statistical analysis; BY wrote the first draft of the manuscript; WL and MD revised the section of the manuscript. All authors contributed to manuscript revision, read and approved the submitted version.

Ethics approval and consent to participate

Not applicable.

\section{Consent for publication}

Not applicable.

\section{Competing interests}

The authors declare that they have no competing interests.

\section{Author details}

${ }^{1}$ Center for Ecological Forecasting and Global Change|, College of Forestry, Northwest A\&F University, Yangling 712100, Shaanxi, China. ${ }^{2}$ Department of Biology Sciences, Institute of Environment Sciences, University of Quebec at Montreal, C.P. 8888, Succ. Center-Ville, Montreal H3C 3P8, Canada. ${ }^{3}$ State Environmental Protection Key Laboratory of Wetland Ecology and Vegetation Restoration, Institute for Peat and Mire Research, Northeast Normal University, Changchun 130024, Jilin, China.

Received: 26 November 2018 Accepted: 22 March 2019

Published online: 13 April 2019

\section{References}

Adams HD, Germino MJ, Breshears DD, Barron-Gafford GA, Guardiola-Claramonte M, Zou CB, Huxman TE (2013) Nonstructural leaf carbohydrate dynamics of Pinus edulis during drought-induced tree mortality reveal role for carbon metabolism in mortality mechanism. New Phytol 197:1142-1151. https://doi. org/10.1111/nph.12102

Adams HD, Guardiola-Claramonte M, Barron-Gafford GA, Villegas JC, Breshears DD, Zou CB, Troch PA, Huxman TE (2009) Temperature sensitivity of droughtinduced tree mortality portends increased regional die-off under globalchange-type drought. Proc Natl Acad Sci U S A 106:7063-7066. https://doi. org/10.1073/pnas.0901438106

Adams HD, Zeppel MJB, Anderegg WRL, Hartmann H, Landhausser SM, Tissue DT, Huxman TE, Hudson PJ, Franz TE, Allen CD, Anderegg LDL, Barron-Gafford GA, Beerling DJ, Breshears DD, Brodribb TJ, Bugmann H, Cobb RC, Collins AD, Dickman LT, Duan H, Ewers BE, Galiano L, Galvez DA, Garcia-Forner N, Gaylord ML, Germino MJ, Gessler A, Hacke UG, Hakamada R, Hector A, Jenkins MW, Kane JM, Kolb TE, Law DJ, Lewis JD, Limousin JM, Love DM, Macalady AK, Martinez-Vilalta J, Mencuccini M, Mitchell PJ, Muss JD, O'Brien MJ, O'Grady AP, Pangle RE, Pinkard EA, Piper FI, Plaut JA, Pockman WT, Quirk J, Reinhardt K, Ripullone F, Ryan MG, Sala A, Sevanto S, Sperry JS, Vargas R, Vennetier M, Way DA, Xu C, Yepez EA, McDowell NG (2017) A multi-species synthesis of physiological mechanisms in drought-induced tree mortality. Nat Ecol Evol 1:1285-1291. https://doi.org/10.1038/s41559-017-0248-x

Allen CD, Macalady AK, Chenchouni H, Bachelet D, McDowell N, Vennetier M, Kitzberger T, Rigling A, Breshears DD, Hogg EH, Gonzalez P, Fensham R, Zhang Z, Castro J, Demidova N, Lim J-H, Allard G, Running SW, Semerci A, Cobb N (2010) A global overview of drought and heat-induced tree mortality reveals emerging climate change risks for forests. For Ecol Manag 259:660-684. https://doi.org/10.1016/j.foreco.2009.09.001

Anderegg WRL, Anderegg LDL (2013) Hydraulic and carbohydrate changes in experimental drought-induced mortality of saplings in two conifer species. Tree Physiol 33:252-260. https://doi.org/10.1093/treephys/tpt016

Barbaroux C, Breda N (2002) Contrasting distribution and seasonal dynamics of carbohydrate reserves in stem wood of adult ring-porous sessile oak and diffuse-porous beech trees. Tree Physiol 22:1201-1210. https://doi.org/10. 1093/treephys/22.17.1201

Barbaroux C, Breda N, Dufrene E (2003) Distribution of above-ground and belowground carbohydrate reserves in adult trees of two contrasting broad-leaved species (Quercus petraea and Fagus sylvatica). New Phytol 157:605-615. https://doi.org/10.1046/j.1469-8137.2003.00681.x 
Beier C, Beierkuhnlein C, Wohlgemuth T, Penuelas J, Emmett B, Körner C, de Boeck H, Christensen JH, Leuzinger S, Janssens IA, Hansen K (2012) Precipitation manipulation experiments - challenges and recommendations for the future. Ecol Lett 15:899-911. https://doi.org/10.1111/j.1461-0248.2012. 01793.x

Bellasio C, Fini A, Ferrini F (2014) Evaluation of a high throughput starch analysis optimised for wood. PLoS One 9:e86645. https://doi.org/10.1371/journal. pone.0086645

Board JE (2008) Waterlogging effects on plant nutrient concentrations in soybean. J Plant Nutr 31:828-838. https://doi.org/10.1080/ 01904160802043122

Bonan GB (2008) Forests and climate change: forcings, feedbacks, and the climate benefits of forests. Science 320:1444-1449. https://doi.org/10.1126/ science. 1155121

Bréda N, Granier A (1996) Intra- and interannual variations of transpiration, leaf area index and radial growth of a sessile oak stand (Quercus petraea). Ann For Sci 53:521-536. https://doi.org/10.1051/forest:19960232

Bréda N, Huc R, Granier A, Dreyer E (2006) Temperate forest trees and stands under severe drought: a review of ecophysiological responses, adaptation processes and long-term consequences. Ann For Sci 63:625-644. https://doi. org/10.1051/forest:2006042

Cao Y, Li Y, Chen Y (2018) Non-structural carbon, nitrogen, and phosphorus between black locust and chinese pine plantations along a precipitation gradient on the loess plateau, China. Trees 32:835-846. https://doi.org/10. 1007/s00468-018-1676-1

Chantuma P, Lacointe A, Kasemsap P, Thanisawanyangkura S, Gohet E, Clement A, Guilliot A, Ameglio T, Thaler P (2009) Carbohydrate storage in wood and bark of rubber trees submitted to different level of $C$ demand induced by latex tapping. Tree Physiol 29:1021-1031. https://doi.org/10.1093/treephys/ tpp043

Cheng W-H, Endo A, Zhou L, Penney J, Chen H-C, Arroyo A, Leon P, Nambara E, Asami T, Seo M, Koshiba T, Sheen J (2002) A unique short-chain dehydrogenase/reductase in arabidopsis glucose signaling and abscisic acid biosynthesis and functions. Plant Cell 14:2723-2743. https://doi.org/10.1105/ tpc.006494

Day TA, Ruhland CT, Xiong FS (2008) Warming increases aboveground plant biomass and $\mathrm{C}$ stocks in vascular-plant-dominated Antarctic tundra. Glob Chang Biol 14:1827-1843. https://doi.org/10.1111/j.1365-2486.2008.01623.x

Dietze MC, Moorcroft PR (2011) Tree mortality in the eastern and Central United States: patterns and drivers. Glob Chang Biol 17:3312-3326. https://doi.org/ 10.1111/j.1365-2486.2011.02477.x

Dietze MC, Sala A, Carbone MS, Czimczik Cl, Mantooth JA, Richardson AD, Vargas R (2014) Nonstructural carbon in woody plants. Annu Rev Plant Biol 65:667687. https://doi.org/10.1146/annurev-arplant-050213-040054

Ditmarova L, Kurjak D, Palmroth S, Kmet J, Strelcova K (2010) Physiological responses of Norway spruce (Picea abies) seedlings to drought stress. Tree Physiol 30:205-213. https://doi.org/10.1093/treephys/tpp116

Dreyer E (1994) Compared sensitivity of seedlings from 3 woody species (Quercus robur L., Quercus rubra L. and Fagus silvatica L.) to water-logging and associated root hypoxia: effects on water relations and photosynthesis. Ann For Sci 51:417-428. https://doi.org/10.1051/forest:19940407

Edwards NT, Hanson PJ (1996) Stem respiration in a closed-canopy upland oak forest. Tree Physiol 16:433-439. https://doi.org/10.1093/treephys/16.4.433

Fatichi S, Leuzinger S, Körner C (2014) Moving beyond photosynthesis: from carbon source to sink-driven vegetation modeling. New Phytol 201:10861095. https://doi.org/10.1111/nph.12614

Frye J, Grosse W (1992) Growth responses to flooding and recovery of deciduous trees. Zeitschrift für Naturforschung C 47:683-689. https://doi.org/10.1515/ znc-1992-9-1008

Galvez DA, Landhäusser SM, Tyree MT (2013) Low root reserve accumulation during drought may lead to winter mortality in poplar seedlings. New Phytol 198:139-148. https://doi.org/10.1111/nph.12129

Glenz C, Schlaepfer R, lorgulescu I, Kienast F (2006) Flooding tolerance of central European tree and shrub species. For Ecol Manag 235:1-13. https://doi.org/ 10.1016/j.foreco.2006.05.065

Grey V, Livesley SJ, Fletcher TD, Szota C (2018) Establishing street trees in stormwater control measures can double tree growth when extended waterlogging is avoided. Landscape Urban Plan 178:122-129. https://doi.org/ 10.1016/j.landurbplan.2018.06.002

Guadagno CR, Ewers BE, Speckman HN, Aston TL, Huhn BJ, DeVore SB, Ladwig JT, Strawn RN, Weinig C (2017) Dead or alive? Using membrane failure and chlorophyll a fluorescence to predict plant mortality from drought. Plant Physiol 175:223-234. https://doi.org/10.1104/pp.16.00581

Handa S, Bressan RA, Handa AK, Carpita NC, Hasegawa PM (1983) Solutes contributing to osmotic adjustment in cultured plant cells adapted to water stress. Plant Physiol 73:834-843. https://doi.org/10.1104/pp.73.3.834

Hartmann H, Adams HD, Anderegg WRL, Jansen S, Zeppel MJB (2015) Research frontiers in drought-induced tree mortality: crossing scales and disciplines. New Phytol 205:965-969. https://doi.org/10.1111/nph.13246

Hartmann H, Trumbore S (2016) Understanding the roles of nonstructural carbohydrates in forest trees - from what we can measure to what we want to know. New Phytol 211:386-403. https://doi.org/10.1111/nph.13955

Hartmann H, Ziegler W, Trumbore S (2013) Lethal drought leads to reduction in nonstructural carbohydrates in Norway spruce tree roots but not in the canopy. Funct Ecol 27:413-427. https://doi.org/10.1111/1365-2435.12046

Hoch G, Richter A, Korner C (2003) Non-structural carbon compounds in temperate forest trees. Plant Cell Environ 26:1067-1081. https://doi.org/10. 1046/j.0016-8025.2003.01032.x

Hsiao TC (1973) Plant responses to water stress. Ann Rev Plant Physiol 24:519570. https://doi.org/10.1146/annurev.pp.24.060173.002511

Huntington KW, Blythe AE, Hodges KV (2006) Climate change and late Pliocene acceleration of erosion in the Himalaya. Earth Planet Sci Lett 252:107-118. https://doi.org/10.1016/j.epsl.2006.09.031

Ismail AM (2018) Submergence tolerance in rice: resolving a pervasive quandary. New Phytol 218:1298-1300. https://doi.org/10.1111/nph.15188

Kagan IA, Kirch BH, Thatcher CD, Teutsch CD, Pleasant RS (2014) Chromatographic profiles of nonstructural carbohydrates contributing to the colorimetrically determined fructan, ethanol-soluble, and water-soluble carbohydrate contents of five grasses. Anim Feed Sci Technol 188:53-63. https://doi.org/10.1016/j.anifeedsci.2013.10.017

Klein T, Siegwolf RTW, Korner C (2016) Belowground carbon trade among tall trees in a temperate forest. Science 352:342-344. https://doi.org/10.1126/ science.aad6188

Korner C (2003) Carbon limitation in trees. J Ecol 91:4-17. https://doi.org/10.1046/ j.1365-2745.2003.00742.x

Kozlowski TT (1992) Carbohydrate sources and sinks in woody plants. Bot Rev 58: 107-222. https://doi.org/10.1007/bf02858600

Kozlowski TT, Pallardy SG (2002) Acclimation and adaptive responses of woody plants to environmental stresses. Bot Rev 68:270-334

Landhäusser SM, Lieffers VJ (2011) Defoliation increases risk of carbon starvation in root systems of mature aspen. Trees 26:653-661. https://doi.org/10.1007/ s00468-011-0633-z

Latt CR, Nair PKR, Kang BT (2001) Reserve carbohydrate levels in the boles and structural roots of five multipurpose tree species in a seasonally dry tropical climate. For Ecol Manag 146:145-158. https://doi.org/10.1016/s0378$1127(00) 00456-4$

León P, Sheen J (2003) Sugar and hormone connections. Trends Plant Sci 8:110116. https://doi.org/10.1016/s1360-1385(03)00011-6

Li H, Cai J, Jiang D, Liu F, Dai T, Cao W (2013a) Carbohydrates accumulation and remobilization in wheat plants as influenced by combined waterlogging and shading stress during grain filling. J Agron Crop Sci 199:38-48. https://doi. org/10.1111/j.1439-037x.2012.00532x

Li MH, Cherubini P, Dobbertin M, Arend M, Xiao WF, Rigling A (2013b) Responses of leaf nitrogen and mobile carbohydrates in different Quercus species/ provenances to moderate climate changes. Plant Biol 15:177-184. https://doi. org/10.1111/j.1438-8677.2012.00579.x

Li P, Wind JJ, Shi X, Zhang H, Hanson J, Smeekens SC, Teng S (2011) Fructose sensitivity is suppressed in Arabidopsis by the transcription factor ANAC089 lacking the membrane-bound domain. Proc Natl Acad Sci U S A 108:34363441. https://doi.org/10.1073/pnas.1018665108

Luan H, Shen H, Pan Y, Guo B, Lv C, Xu R (2018) Elucidating the hypoxic stress response in barley (Hordeum vulgare L.) during waterlogging: a proteomics approach. Sci Rep 8:9655. https://doi.org/10.1038/s41598-018-27726-1

Mantovani D, Veste M, Freese D (2014) Effects of drought frequency on growth performance and transpiration of young black locust (Robinia pseudoacacia L. ). Intl J Forest Res. https://doi.org/10.1155/2014/821891

Mauchly JW (1940) Significance test for sphericity of a normal $n$-variate distribution. Ann Math Stat 11:204-209. https://doi.org/10.1214/aoms/ 1177731915

McDowell N, Pockman WT, Allen CD, Breshears DD, Cobb N, Kolb T, Plaut J, Sperry J, West A, Williams DG, Yepez EA (2008b) Mechanisms of plant survival and mortality during drought: why do some plants survive while others 
succumb to drought? New Phytol 178:719-739. https://doi.org/10.1111/j. 1469-8137.2008.02436.x

McDowell NG, Beerling DJ, Breshears DD, Fisher RA, Raffa KF, Stitt M (2011) The interdependence of mechanisms underlying climate-driven vegetation mortality. Trends Ecol Evol 26:523-532. https://doi.org/10.1016/j.tree.2011.06.003

McDowell NG, Pockman WT, Allen CD, Breshears DD, Cobb N, Kolb T, Plaut J, Sperry J, West A, Williams DG (2008a) Mechanisms of plant survival and mortality during drought: why do some plants survive while others succumb to drought? New Phytol 178:719-739. https://doi.org/10.1111/j.1469-8137. 2008.02436.x

McDowell NG, Sevanto S (2010) The mechanisms of carbon starvation: how, when, or does it even occur at all? New Phytol 186:264-266. https://doi.org/ 10.1111/j.1469-8137.2010.03232.x

Michelot A, Simard S, Rathgeber C, Dufrene E, Damesin C (2012) Comparing the intra-annual wood formation of three European species (Fagus sylvatica, Quercus petraea and Pinus sylvestris) as related to leaf phenology and nonstructural carbohydrate dynamics. Tree Physiol 32:1033-1045. https://doi.org/ 10.1093/treephys/tps052

Millard P, Sommerkorn M, Grelet G-A (2007) Environmental change and carbon limitation in trees: a biochemical, ecophysiological and ecosystem appraisal. New Phytol 175:11-28. https://doi.org/10.1111/j.1469-8137.2007.02079.x

Miller G, Shulaev V, Mittler R (2008) Reactive oxygen signaling and abiotic stress. Physiol Plant 133:481-489. https://doi.org/10.1111/j.1399-3054.2008.01090.x

Minucci JM, Miniat CF, Teskey RO, Wurzburger N (2017) Tolerance or avoidance: drought frequency determines the response of an $\mathrm{N}_{2}$-fixing tree. New Phytol 215:434-442. https://doi.org/10.1111/nph.14558

Müller J, Boller T, Wiemken A (2001) Trehalose becomes the most abundant nonstructural carbohydrate during senescence of soybean nodules. J Exp Bot 52: 943-947. https://doi.org/10.1093/jexbot/52.358.943

Nguyen LTT, Osanai Y, Anderson IC, Bange MP, Tissue DT, Singh BK (2018) Flooding and prolonged drought have differential legacy impacts on soil nitrogen cycling, microbial communities and plant productivity. Plant Soil 431:371-387. https://doi.org/10.1007/s11104-018-3774-7

O'Grady AP, Mitchell PJM, Pinkard EA, Tissue DT (2013) Thirsty roots and hungry leaves: unravelling the roles of carbon and water dynamics in tree mortality. New Phytol 200:294-297. https://doi.org/10.1111/nph.12451

Osakabe Y, Osakabe K, Shinozaki K, Tran L-SP (2014) Response of plants to water stress. Front Plant Sci 5:86. https://doi.org/10.3389/fpls.2014.00086

Pachauri RK, Allen MR, Barros VR, Broome J, Cramer W, Christ R, Church JA, Clarke L, Dahe Q, Dasgupta P, Dubash NK, Edenhofer O, Elgizouli I, Field CB, Forster P, Friedlingstein P, Fuglestvedt J, Gomez-Echeverri L, Hallegatte S, Hegerl G, Howden M, Jiang K, Jimenez CB, Kattsov V, Lee H, Mach KJ, Marotzke J, Mastrandrea MD, Meyer L, Minx J, Mulugetta Y, O'Brien K, Oppenheimer M, Pereira JJ, Pichs-Madruga R, Plattner G-K, Pörtner H-O, Power SB, Preston B, Ravindranath NH, Reisinger A, Riahi K, Rusticucci M, Scholes R, Seyboth K, Sokona Y, Stavins R, Stocker TF, Tschakert P, van Vuuren D, van Ypserle J-P (2014) Climate change 2014: synthesis report. Contribution of working groups I, II and III to the fifth assessment report of the intergovernmental panel on climate change. IPCC, Geneva

Palacio S, Hoch G, Sala A, Körner C, Millard P (2014) Does carbon storage limit tree growth? New Phytol 201:1096-1100. https://doi.org/10.1111/nph.12602

Pantin F, Fanciullino A-L, Massonnet C, Dauzat M, Simonneau T, Muller B (2013) Buffering growth variations against water deficits through timely carbon usage. Front Plant Sci 4:483. https://doi.org/10.3389/fpls.2013.00483

Parent C, Nicolas C, Audrey B, Crevècoeur M, Dat J (2008) An overview of plant responses to soil waterlogging. Plant Stress 2:20-27

Parker J, Patton RL (1975) Effects of drought and defoliation on some metabolites in roots of black oak seedlings. Can J For Res 5:457-463. https:// doi.org/10.1139/x75-063

Patz JA, Campbell-Lendrum D, Holloway T, Foley JA (2005) Impact of regional climate change on human health. Nature 438:310-317. https://doi.org/10 1038/nature04188

Pezeshki SR, DeLaune RD (1996) Responses of Spartina alterniflora and Spartina patens to rhizosphere oxygen deficiency. Acta Oecol 17:365-378

Pretzsch H, Schütze G, Biber P (2018) Drought can favour the growth of small in relation to tall trees in mature stands of Norway spruce and European beech. Forest Ecosystems 5:20. https://doi.org/10.1186/s40663-018-0139-x

Quentin AG, Pinkard EA, Ryan MG, Tissue DT, Baggett LS, Adams HD, Maillard P, Marchand J, Landhausser SM, Lacointe A, Gibon Y, Anderegg WR, Asao S, Atkin OK, Bonhomme M, Claye C, Chow PS, Clement-Vidal A, Davies NW, Dickman LT, Dumbur R, Ellsworth DS, Falk K, Galiano L, Grunzweig JM,
Hartmann H, Hoch G, Hood S, Jones JE, Koike T, Kuhlmann I, Lloret F, Maestro M, Mansfield SD, Martinez-Vilalta J, Maucourt M, McDowell NG, Moing A, Muller B, Nebauer SG, Niinemets U, Palacio S, Piper F, Raveh E, Richter A, Rolland G, Rosas T, Joanis BS, Sala A, Smith RA, Sterck F, Stinziano JR, Tobias M, Unda F, Watanabe M, Way DA, Weerasinghe LK, Wild B, Wiley E, Woodruff DR (2015) Non-structural carbohydrates in woody plants compared among laboratories. Tree Physiol 35:1146-1165. https://doi.org/10.1093/ treephys/tpv073

Raessler M, Wissuwa B, Breul A, Unger W, Grimm T (2010) Chromatographic analysis of major non-structural carbohydrates in several wood species - an analytical approach for higher accuracy of data. Analyt Method 2:532-538. https://doi.org/10.1039/b9ay00193j

Regier N, Streb S, Cocozza C, Schaub M, Cherubini P, Zeeman SC, Frey B (2009) Drought tolerance of two black poplar (Populus nigra L.) clones: contribution of carbohydrates and oxidative stress defence. Plant Cell Environ 32:17241736. https://doi.org/10.1111/j.1365-3040.2009.02030.x

Regier N, Streb S, Zeeman SC, Frey B (2010) Seasonal changes in starch and sugar content of poplar (Populus deltoides $\times$ nigra cv. Dorskamp) and the impact of stem girdling on carbohydrate allocation to roots. Tree Physiol 30: 979-987. https://doi.org/10.1093/treephys/tpq047

Richardson AD, Carbone MS, Huggett BA, Furze ME, Czimczik Cl, Walker JC, Xu X, Schaberg PG, Murakami P (2015) Distribution and mixing of old and new nonstructural carbon in two temperate trees. New Phytol 206:590-597. https://doi.org/10.1111/nph.13273

Richardson AD, Carbone MS, Keenan TF, Czimczik Cl, Hollinger DY, Murakami P, Schaberg PG, Xu X (2013) Seasonal dynamics and age of stemwood nonstructural carbohydrates in temperate forest trees. New Phytol 197:850861. https://doi.org/10.1111/nph.12042

Ryan MG (2011) Tree responses to drought. Tree Physiol 31:237-239. https://doi. org/10.1093/treephys/tpr022

Saffell BJ, Meinzer FC, Woodruff DR, Shaw DC, Voelker SL, Lachenbruch B, Falk K (2014) Seasonal carbohydrate dynamics and growth in Douglas-fir trees experiencing chronic, fungal-mediated reduction in functional leaf area. Tree Physiol 34:218-228. https://doi.org/10.1093/treephys/tpu002

Sairam RK, Kumutha D, Ezhilmathi K, Deshmukh PS, Srivastava GC (2008) Physiology and biochemistry of waterlogging tolerance in plants. Biol Plant 52:401-412. https://doi.org/10.1007/s10535-008-0084-6

Sala A (2009) Lack of direct evidence for the carbon-starvation hypothesis to explain drought-induced mortality in trees. Proc Natl Acad Sci U S A 106: E68-E68. https://doi.org/10.1073/pnas.0904580106

Sala A, Piper F, Hoch G (2010) Physiological mechanisms of drought-induced tree mortality are far from being resolved. New Phytol 186:274-281. https://doi. org/10.1111/j.1469-8137.2009.03167.x

Sala A, Woodruff DR, Meinzer FC (2012) Carbon dynamics in trees: feast or famine? Tree Physiol 32:764-775. https://doi.org/10.1093/treephys/tpr143

Saud P, Cram DS, Lynch TB, Guldin JM (2018) Effects of ice damage on growth and survival of shortleaf pine trees, pp 293-294

Saud P, Lynch TB, Guldin JM (2016) Twenty five years long survival analysis of an individual shortleaf pine trees, pp 555-557

Scartazza A, Moscatello S, Matteucci G, Battistelli A, Brugnoli E (2013) Seasonal and inter-annual dynamics of growth, non-structural carbohydrates and $C$ stable isotopes in a Mediterranean beech forest. Tree Physiol 33:730-742. https://doi.org/10.1093/treephys/tpt045

Sevanto S, McDowell NG, Dickman LT, Pangle R, Pockman WT (2014) How do trees die? A test of the hydraulic failure and carbon starvation hypotheses. Plant Cell Environ 37:153-161. https://doi.org/10.1111/pce.12141

Sheen J (2014) Master regulators in plant glucose signaling networks. J Plant Biol 57:67-79. https://doi.org/10.1007/s12374-014-0902-7

Silva EN, Ferreira-Silva SL, Viégas RA, Silveira JAG (2010) The role of organic and inorganic solutes in the osmotic adjustment of drought-stressed Jatropha curcas plants. Environ Exp Bot 69:279-285. https://doi.org/10.1016/j. envexpbot.2010.05.001

Tauzin AS, Giardina T (2014) Sucrose and invertases, a part of the plant defense response to the biotic stresses. Front Plant Sci 5:293. https://doi.org/10.3389/ fpls.2014.00293

Thomas SC, Martin AR (2012) Carbon content of tree tissues: a synthesis. Forests 3:332-352. https://doi.org/10.3390/f3020332

Vartapetian BB, Jackson MB (1997) Plant adaptations to anaerobic stress. Ann Bot 79:3-20. https://doi.org/10.1093/oxfordjournals.aob.a010303

Villar-Salvador P, Ocaña L, Peñuelas J, Carrasco I (1999) Effect of water stress conditioning on the water relations, root growth capacity, and the nitrogen 
and non-structural carbohydrate concentration of Pinus halepensis mill (Aleppo pine) seedlings. Ann Sci For 56:459-465. https://doi.org/10.1051/ forest:19990602

Villar-Salvador P, Uscola M, Jacobs DF (2015) The role of stored carbohydrates and nitrogen in the growth and stress tolerance of planted forest trees. New For 46:813-839. https://doi.org/10.1007/s11056-015-9499-z

Wiley E (2013) Towards a better understanding of nonstructural carbohydrate storage and carbon limitation in trees. Dissertation, University of Pennsylvania

Williams AP, Allen CD, Macalady AK, Griffin D, Woodhouse CA, Meko DM, Swetnam TW, Rauscher SA, Seager R, Grissino-Mayer HD, Dean JS, Cook ER, Gangodagamage C, Cai M, McDowell NG (2012) Temperature as a potent driver of regional forest drought stress and tree mortality. Nat Clim Chang 3: 292-297. https://doi.org/10.1038/nclimate1693

Wilson R, Cataldo A, Andersen CP (1995) Determination of total nonstructural carbohydrates in tree species by high-performance anion-exchange chromatography with pulsed amperometric detection. Can J For Res 25: 2022-2028. https://doi.org/10.1139/X95-218

Würth MKR, Peláez-Riedl S, Wright SJ, Körner C (2005) Non-structural carbohydrate pools in a tropical forest. Oecologia 143:11-24. https://doi.org/ 10.1007/s00442-004-1773-2

Yemm EW, Willis AJ (1954) The estimation of carbohydrates in plant extracts by anthrone. Biochem J 57:508-514. https://doi.org/10.1042/bj0570508

Zhang H, Wang C, Wang X (2014) Spatial variations in non-structural carbohydrates in stems of twelve temperate tree species. Trees 28:77-89. https://doi.org/10.1007/s00468-013-0931-8

Zhang T, Cao Y, Chen Y, Liu G (2015) Non-structural carbohydrate dynamics in Robinia pseudoacacia saplings under three levels of continuous drought stress. Trees 29:1837-1849. https://doi.org/10.1007/s00468-015-1265-5

\section{Submit your manuscript to a SpringerOpen ${ }^{\circ}$ journal and benefit from:}

- Convenient online submission

- Rigorous peer review

- Open access: articles freely available online

- High visibility within the field

Retaining the copyright to your article

Submit your next manuscript at $\boldsymbol{\nabla}$ springeropen.com 